\title{
Establishing paediatric reference intervals for thyroid function tests in Croatian population on the Abbott Architect i2000
}

\author{
Adriana Bokulić*1, Ivana Zec' ${ }^{1}$ Domagoj Marijančević', Sanja Goreta', Marija Požgaj Šepec², Lavinia La Grasta Sabolić2 \\ ${ }^{1}$ Laboratory of Endocrinology, Department of Oncology and Nuclear Medicine, Sestre Milosrdnice University Hospital Center, Zagreb, \\ Croatia \\ ${ }^{2}$ Department of Paediatrics, Sestre Milosrdnice University Hospital Center, Zagreb, Croatia \\ ${ }^{*}$ Corresponding author: adriana.bokulic@kbcsm.hr
}

\begin{abstract}
Introduction: Evaluation of thyroid function is often requested and therefore defining paediatric reference intervals (RIs) is of vital importance. Currently, there is a distinct lack of paediatric Rls for thyroid function tests in Croatia. Thus, we established Rls for thyroid stimulating hormone (TSH), total triiodothyronine (TT3), total thyroxine (TT4), free triiodothyronine (FT3) and free thyroxine (FT4) in the Croatian paediatric population.

Materials and methods: Reference intervals were calculated from 397 apparently healthy children, aged from 2 days to $<19$ years. Serum samples were analysed for thyroid function tests on the Abbott Architect i2000. Age- and sex-specific $95 \%$ Rls with $90 \%$ confidence intervals were established according to Clinical and Laboratory Standards Institute guidelines. To express the magnitude of sex and age variation, standard deviation ratio (SDR) was calculated using two-level nested ANOVA. The criterion for considering partitioning reference values was set to SDR $>0.3$.

Results: All thyroid function tests required age partitioning, confirmed by SDR above 0.3 . There was no need for sex partitioning, confirmed by SDR below 0.3. Still, FT3 was partitioned due to visually noticeable sex related difference for the oldest group (12 years to $<19$ years).

Conclusion: This is the first study to establish Rls for thyroid function tests in the Croatian paediatric population. We propose Rls for widely used Abbott platform, thus giving laboratories method- and population-specific paediatric Rls for thyroid function tests that should improve clinical test interpretation.
\end{abstract}

Keywords: paediatric; reference values; thyroid function tests; immunoassay; standard deviation ratio

\section{Introduction}

Reference interval (RI) is commonly defined as range of values within two reference limits, including the limits themselves (1). It represents an important tool, which aids clinicians in diagnosing, making therapeutic decisions, monitoring, and generally in differentiation between healthy and non-healthy individuals. Establishing paediatric specific Rls, despite being a difficult and sensitive task, became an essential demand for appropriate patient management (2).

The assessment of thyroid function is the most frequently applied endocrine investigation in chil- dren and adolescents. An important aspect of thyroid function is the dynamic change that takes place during growth and development (3). Although interpretation of thyroid function tests is similar to that applied in adults, the Rls differ since they depend on the maturation of the hypothalamic-pituitary-thyroid axis. Adult RIs are often the only available ones when interpreting laboratory results for paediatric population. Relying solely on adult Rls could however lead to unnecessary diagnostic procedures and erroneous therapeutic decisions. Hence, it is essential to use appropriate 
age-related Rls and to interpret results based on a thorough knowledge of thyroid physiology from neonatal age to adulthood (4).

In the last decade, there were multiple published studies with RIs for thyroid hormones in children and adolescents (5). Differences in study design and method of measurement create difficulties when comparing these results. Furthermore, it is well known that the Abbott Architect method produces lower TSH results, which leads to lower TSH values in studies using this method (6-9). Even in studies using the same method, the differences are still present due to variability in subject recruitment (hospital patients vs healthy children), ageand sex- partitioning, ethnicity and iodine status of studied population (10-14).

Croatian laboratories are responsible for providing appropriate RIs for local population. Usually, they rely on literature data derived from other populations and verify them according to Clinical and Laboratory Standards Institute (CLSI) protocol before implementation $(1,15)$. The concentration of thyroid hormones can be influenced by multiple factors other than age and sex, such as ethnicity, iodine status and body mass index (16-18). Currently, there is a distinct lack of paediatric Rls for thyroid function tests in Croatia.

We intended to establish Rls for thyroid function tests including thyroid stimulating hormone (TSH), total triiodothyronine (TT3), total thyroxine (TT4), free triiodothyronine (FT3) and free thyroxine (FT4) in the Croatian paediatric population. The method-specific RIs empirically determined in this study are expected to improve the quality of the immunoassay interpretation for paediatric care in many hospitals and clinical laboratories using the Abbott platform for their automated immunoassay testing.

\section{Materials and methods}

\section{Subjects}

The study population was prospectively recruited from October 2018 to July 2020 in the University Hospital Center Sestre milosrdnice, Zagreb, Croa- tia. The study was approved by hospital's Ethics Review Board. In total, 444 apparently healthy children, 207 males and 237 females, younger than 19 years of age entered the study. Residual serum samples were collected from routinely ordered laboratory requests from paediatric outpatients and maternity ward. Subjects were recruited by two experienced paediatricians according to inclusion and exclusion criteria. Inclusion criteria were defined as: age $<19$ years, personal medical history and clinical examination non-suggestive of thyroid disease. Subject were excluded if any of the following criteria have been met: premature birth (for neonates), established chronic disease, acute illness within 7 days of collection, intake of medications known to affect serum concentration of thyroid hormones, body mass index below 5 or above 95 percentiles for age and sex. Samples with thyroid peroxidase antibody (TPO-Ab) and thyroglobulin antibody (TG-Ab) results above manufacturer's declared cut-off value of $5.6 \mathrm{kU} / \mathrm{L}$ and $4.1 \mathrm{kU} / \mathrm{L}$, respectively, were excluded except for neonatal samples. Ideally, study should exclude samples with positive TPO-Ab and TG-Ab results, but this would significantly affect number of neonatal samples. Although diffusion of TPO-Ab through placental barrier is possible, the presence of TPO-Ab and TG-Ab in children does not affect estimation of Rls of thyroid function tests $(19,20)$. All subjects fulfilling conditions of inclusion and exclusion criteria were defined as apparently healthy.

\section{Methods}

Neonatal blood samples were collected regardless of the time in the day or fasting state by heel prick in micro tubes $(0.5 \mathrm{~mL}$ MiniCollect, Greiner BioOne $\mathrm{GmbH}$, Kremsmünster, Austria). Other blood samples were collected in fasting state from 7.00 to $10.00 \mathrm{am}$ by venipuncture in test tubes with clot activator (2 or $4 \mathrm{~mL}$ Vacuette, Greiner Bio-One $\mathrm{GmbH}$, Kremsmünster, Austria). After clotting, blood samples were centrifuged at 2200 RCF for 10 minutes.

Fresh serum samples were firstly analysed for TPO$\mathrm{Ab}$ and TG-Ab. If antibodies tested negative, sam- 
ples were further analysed for TSH, TT3, TT4, FT3 and FT4. Neonatal samples were tested for all hormones irrespective of the antibodies test results. Due to limited volume, not all hormones were measured in each individual sample. All measurements were performed on the Abbott Architect i2000 chemiluminescent microparticle immunoassay (Abbott Diagnostics, Abbott Park, USA). Assay precision was evaluated according to CLSI EP15-A2 guidelines using two levels of quality controls measured in triplicate for five consecutive days (Table 1) (21). Prior to analysis, authorized personnel verified calibrations and quality controls.

\section{Statistical analysis}

Data collection and analysis were performed according to CLSI EP28-A3c guidelines (1). Hormone concentrations were plotted against age and sex. Plotted data were visually inspected for possible age and sex stratification and aberrant results. Shapiro-Wilk test was applied for testing normality. Outliers were tested using Tukey's method and subsequently eliminated. Based on sample numbers $(<120 v s \geq 120$ ) and data distribution (normal vs non-Gaussian) in each subgroup, $95 \%$ Rls with $90 \%$ confidence intervals were calculated with appropriate statistical method as follows: (i) parametric - $\geq 120$ samples with normal distribution; (ii) nonparametric percentile $-\geq 120$ samples with non-Gaussian distribution; (iii) robust - $<120$ samples with normal distribution or after Box-Cox transformation for non-Gaussian distribution. Method proposed by Ichihara and Boyd was used to evaluate the need for partitioning $(22,23)$. The advantage of the nested ANOVA is to evaluate the magnitude of variation between three or more categories. Thus, we used the standard deviation ratio (SDR) for quantification of sex and age-related differences. In summary, two-level nested ANOVA was performed to calculate standard deviations (SD) of reference values for age $\left(S_{\text {Age }}\right)$, sex $\left(\mathrm{SD}_{\mathrm{Sex}}\right)$ and SD attributable to net-between-individual variation $\left(\mathrm{SD}_{\mathrm{B} I}\right)$. Nested ANOVA computation was done after logarithmic transformation of reference values. To express the magnitude of each source of variation, SDR was calculated by dividing $\mathrm{SD}_{\mathrm{Age}}$ and $\mathrm{SD}_{\mathrm{Sex}}$ with $\mathrm{SD}_{\mathrm{Bl}}$. Criterion for considering partitioning reference values was set to SDR $>0.3$. Results were provided through statistical software MedCalc version 19.2.1 (MedCalc Software Ltd, Ostend, Belgium) and Minitab version 19.2 (Minitab Statistical Software, AppOnFly Inc. San Francisco, USA).

\section{Results}

From a total of 444 subjects, 33 samples were excluded due to positive TPO-Ab and/or TG-Ab results. From 88 neonatal samples, 21 were TPO-Ab and/or TG-Ab positive, but were included in the study. After testing for outliers with Tukey method, 397 reference individuals, 187 boys and 210 girls, were selected for establishing Rls. Age- and sexspecific $95 \%$ RIs, $90 \%$ confidence intervals of the lower and upper reference limit and SDRs are presented in Table 2. Figure 1 represents scatter plots

TABLE 1. Assay precision results

\begin{tabular}{|c|c|c|c|c|c|c|}
\hline \multirow[b]{2}{*}{ Analyte (unit) } & \multirow[b]{2}{*}{ Mean } & \multicolumn{2}{|c|}{$\begin{array}{c}\text { Precision (CV\%) } \\
\text { Level } 1\end{array}$} & \multirow[b]{2}{*}{ Mean } & \multicolumn{2}{|c|}{$\begin{array}{c}\text { Precision (CV\%) } \\
\text { Level } 2\end{array}$} \\
\hline & & Within run & Within laboratory & & Within run & Within laboratory \\
\hline TSH (mIU/L) & 0.017 & 3.9 & 4.5 & 3.48 & 1.4 & 1.8 \\
\hline TT3 (nmol/L) & 1.1 & 2.7 & 3.0 & 2.6 & 3.5 & 4.0 \\
\hline TT4 (nmol/L) & 68 & 2.5 & 2.9 & 138 & 3.1 & 3.0 \\
\hline FT3 (pmol/L) & 2.7 & 4.5 & 5.2 & 8.5 & 2.4 & 3.5 \\
\hline FT4 (pmol/L) & 10.9 & 2.3 & 2.4 & 28.7 & 2.8 & 2.5 \\
\hline
\end{tabular}

TSH - thyroid stimulating hormone. TT3 - total triiodothyronine. TT4 - total thyroxine. FT3 - free triiodothyronine. FT4 - free thyroxine. CV - coefficient of variation. 
TABLE 2. Age- and sex-specific reference intervals with standard deviation ratios

\begin{tabular}{|c|c|c|c|c|c|c|c|c|c|c|}
\hline \multirow[b]{2}{*}{$\begin{array}{l}\text { Analyte } \\
\text { (unit) }\end{array}$} & \multirow[b]{2}{*}{ Age group } & \multirow[b]{2}{*}{ Sex } & \multirow[b]{2}{*}{$\mathbf{N}$} & \multirow[b]{2}{*}{ Median } & \multicolumn{4}{|c|}{ Reference interval } & \multicolumn{2}{|c|}{ Nested ANOVA } \\
\hline & & & & & $\begin{array}{l}\text { Lower } \\
\text { limit }\end{array}$ & $\begin{array}{l}\text { Upper } \\
\text { limit }\end{array}$ & $\begin{array}{l}\text { Lower } \\
90 \% \mathrm{Cl}\end{array}$ & $\begin{array}{l}\text { Upper } \\
90 \% \mathrm{Cl}\end{array}$ & SDR $_{\text {Age }}$ & $\mathbf{S D R}_{\text {Sex }}$ \\
\hline \multirow{3}{*}{$\begin{array}{l}\text { TSH } \\
\text { (mIU/L) }\end{array}$} & 2 days to $<2$ months $^{*}$ & $\mathrm{M}+\mathrm{F}$ & 102 & 2.28 & 0.50 & 6.54 & $0.41-0.64$ & $5.71-7.35$ & \multirow{3}{*}{0.34} & \multirow{3}{*}{0.00} \\
\hline & 2 months to $<14$ years $^{\ddagger}$ & $\mathrm{M}+\mathrm{F}$ & 170 & 1.76 & 0.80 & 4.61 & $0.59-0.83$ & $3.83-4.99$ & & \\
\hline & 14 years to $<19$ years $^{\ddagger}$ & $\mathrm{M}+\mathrm{F}$ & 125 & 1.51 & 0.58 & 3.60 & $0.42-0.67$ & $3.14-3.88$ & & \\
\hline \multirow{4}{*}{$\begin{array}{l}\text { TT3 } \\
\text { (nmol/L) }\end{array}$} & 2 days to $<1$ year $^{\dagger}$ & $\mathrm{M}+\mathrm{F}$ & 71 & 2.4 & 1.0 & 3.6 & $0.8-1.3$ & $3.4-3.8$ & \multirow{4}{*}{0.64} & \multirow{4}{*}{0.13} \\
\hline & 1 year to $<6$ years $^{\dagger}$ & $\mathrm{M}+\mathrm{F}$ & 63 & 2.3 & 1.7 & 2.9 & $1.6-1.8$ & 2.8-3.1 & & \\
\hline & 6 years to $<14$ years $^{\dagger}$ & $\mathrm{M}+\mathrm{F}$ & 66 & 2.1 & 1.4 & 2.8 & $1.3-1.5$ & $2.7-2.9$ & & \\
\hline & 14 years to $<19$ years $^{\dagger}$ & $\mathrm{M}+\mathrm{F}$ & 117 & 1.8 & 1.3 & 2.3 & $1.2-1.4$ & $2.2-2.4$ & & \\
\hline \multirow{3}{*}{$\begin{array}{l}\text { TT4 } \\
\text { (nmol/L) }\end{array}$} & 7 days to $<1$ year $^{\dagger}$ & $\mathrm{M}+\mathrm{F}$ & 55 & 134 & 82 & 188 & $73-91$ & $176-199$ & \multirow{3}{*}{1.03} & \multirow{3}{*}{0.00} \\
\hline & 1 year to $<9$ years $^{\dagger}$ & $\mathrm{M}+\mathrm{F}$ & 97 & 114 & 81 & 147 & $77-86$ & $141-152$ & & \\
\hline & 9 years to $<19$ years $^{\S}$ & $\mathrm{M}+\mathrm{F}$ & 148 & 97 & 68 & 126 & $64-71$ & $123-130$ & & \\
\hline \multirow{4}{*}{$\begin{array}{l}\text { FT3 } \\
\text { (pmol/L) }\end{array}$} & 2 days to $<1$ year $^{\dagger}$ & $\mathrm{M}+\mathrm{F}$ & 74 & 4.8 & 2.4 & 7.4 & $2.0-2.8$ & $7.0-7.8$ & \multirow{4}{*}{0.80} & \multirow{4}{*}{0.21} \\
\hline & 1 year to $<12$ years $^{\dagger}$ & $\mathrm{M}+\mathrm{F}$ & 113 & 5.0 & 3.5 & 6.6 & $3.3-3.7$ & $6.3-6.8$ & & \\
\hline & 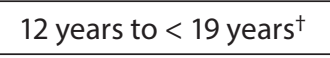 & $M$ & 45 & 4.4 & 3.4 & 6.0 & $3.2-3.7$ & $5.7-6.3$ & & \\
\hline & 12 years to $<19$ years $^{\dagger}$ & $\mathrm{F}$ & 85 & 4.4 & 3.2 & 5.5 & $2.9-3.3$ & $5.3-5.7$ & & \\
\hline \multirow{3}{*}{$\begin{array}{l}\text { FT4 } \\
\text { (pmol/L) }\end{array}$} & 2 days to $<15$ days $^{\dagger}$ & $\mathrm{M}+\mathrm{F}$ & 68 & 19.8 & 11.8 & 28.0 & $10.3-13.1$ & $26.4-29.6$ & \multirow{3}{*}{1.64} & \multirow{3}{*}{0.00} \\
\hline & 15 days to $<1$ year ${ }^{*}$ & $\mathrm{M}+\mathrm{F}$ & 54 & 14.2 & 11.3 & 18.9 & $10.8-11.8$ & $17.7-20.1$ & & \\
\hline & 1 year to $<19$ years $^{\S}$ & $\mathrm{M}+\mathrm{F}$ & 241 & 13.2 & 10.5 & 15.9 & $10.2-10.7$ & $15.7-16.2$ & & \\
\hline
\end{tabular}

TSH - thyroid stimulating hormone. TT3 - total triiodothyronine. TT4 - total thyroxine. FT3 - free triiodothyronine. FT4 - free thyroxine. $\mathrm{M}$ - male. F - female. ${ }^{*}$ Robust method (Box-Cox transformation). ${ }^{\dagger}$ Robust method. ${ }^{\ddagger}$ Nonparametric percentile method. ${ }^{\S}$ Parametric method. SDR Age $_{\text {and }}$ SDR Sex $_{\text {were computed by two-level nested ANOVA. SDR }}$ - standard deviation ratio for between-sex variations. $\mathrm{SDR}_{\mathrm{Age}}$ - standard deviation ratio for between-age variations. $\mathrm{Cl}$ - confidence interval.

of thyroid function tests against age and sex. All Rls are defined beginning with 2-day-old newborns, except TT4. The concentration of TT4 in the first days of life showed grossly scattered data that would affect upper reference limit and widen confidence interval. Since TT4 is not usually requested in new-borns, we decided to exclude results of new-borns younger than 7 days. Significant differences between age partitions were observed in all thyroid function tests with $\mathrm{SDR}_{\text {Age }}$ above 0.3 confirming partitioning data by age is appropriate and justifiable. Calculated SDR $_{\text {sex }}$ showed there is no need for sex stratification for any of the tested hormones. Figure 2 shows the interval plot for the only two analytes with measurable $\mathrm{SDR}_{\mathrm{Sex}^{\prime}}$ TT3 and FT3. Even though $\mathrm{SDR}_{\text {Sex }}$ was less than 0.3, FT3 was partitioned due to noticeable sex related difference for the oldest group (12 years to $<19$ years).

\section{Discussion}

This study establishes age- and sex-specific RIs for thyroid function tests, derived from Croatian paediatric population using Abbott Architect method and confirms the necessity of establishing population specific Rls.

TSH is the first and the most important laboratory test used to evaluate thyroid function. As expected, surge in the concentration of TSH within first two months after birth and wider Rls are comparable to previous studies. With regard to methodmatched group for the new-borns, only two studies reported Rls on the Abbott platform. The best 
A

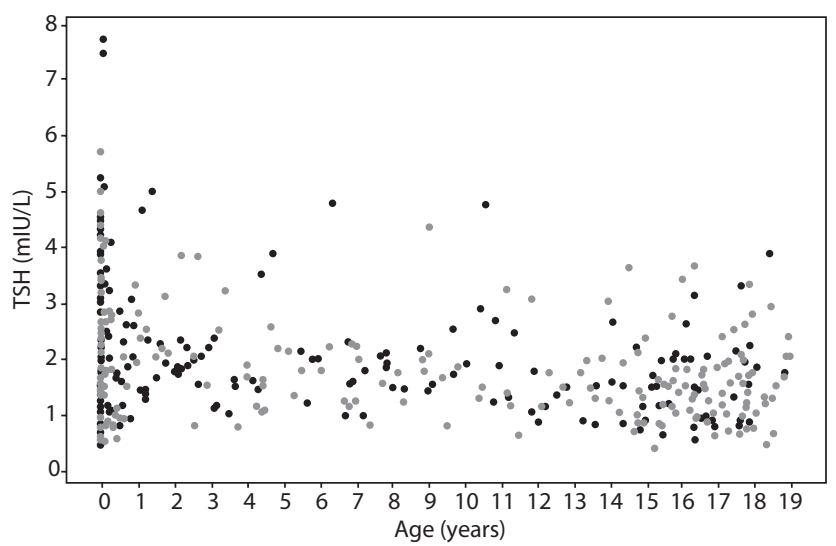

C

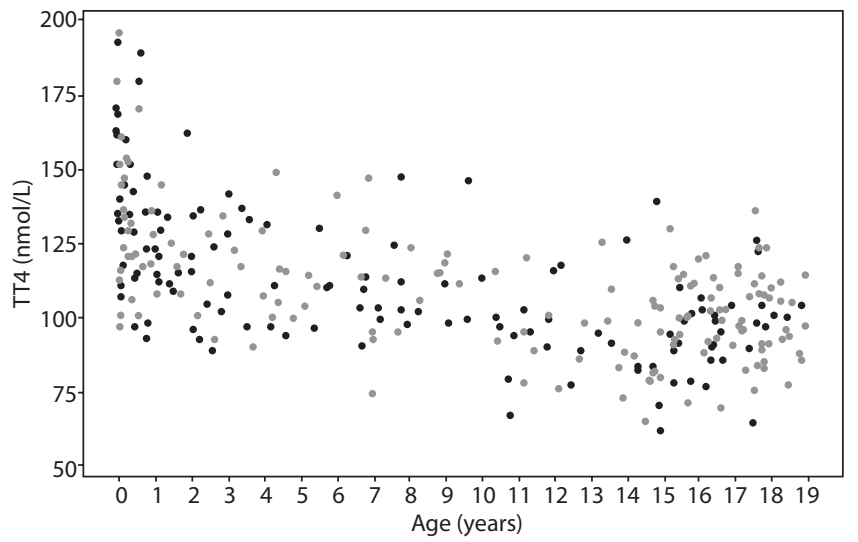

E

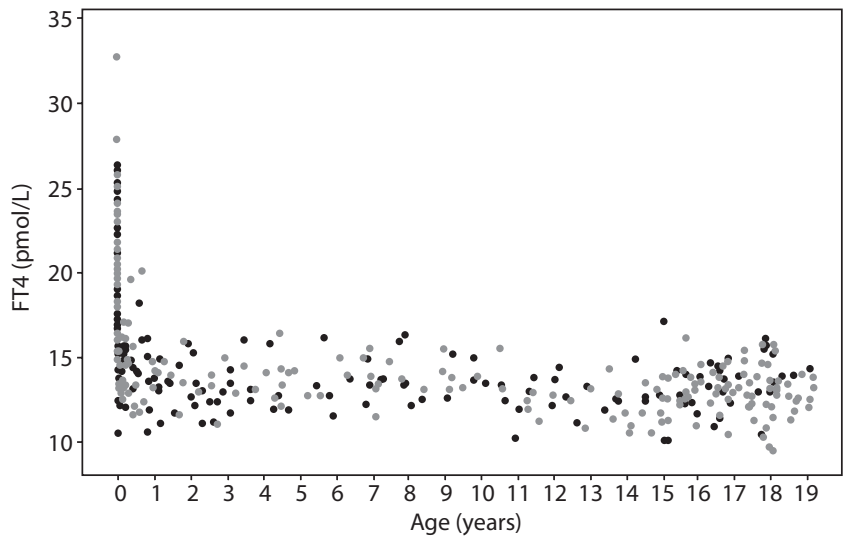

B

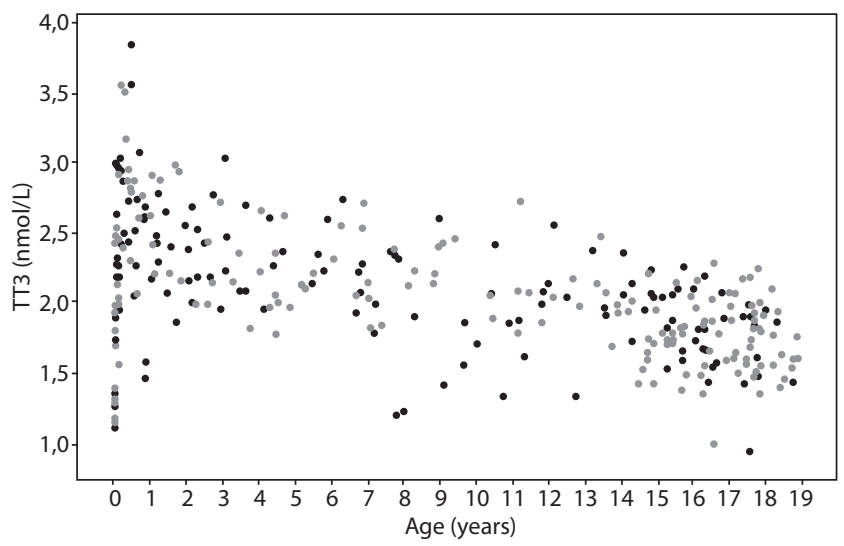

D

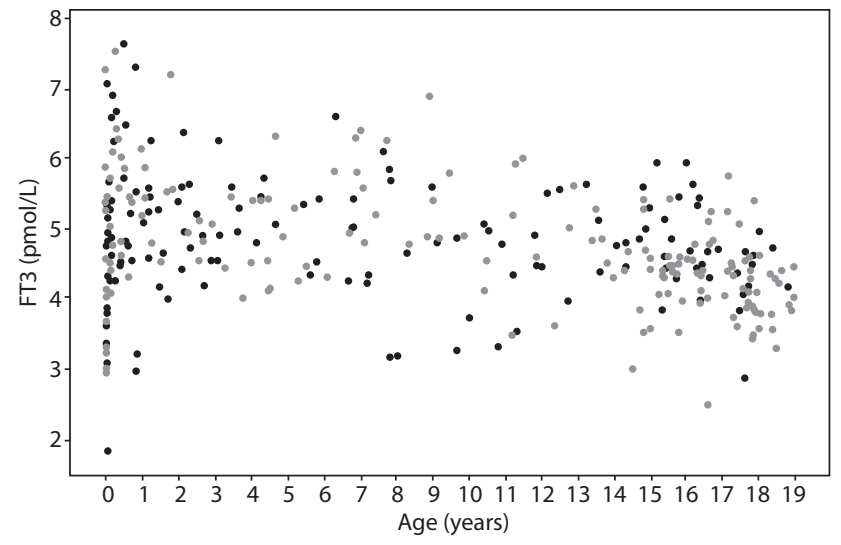

Figure 1. Age-specific scatter plots for thyroid function tests. Males are shown in black, females in grey. (A) TSH - thyroid stimulating hormone; (B) TT3 - total triiodothyronine; (C) TT4 - total thyroxine: (D) FT3 - free triiodothyronine; (E) FT4 - free thyroxine.

agreement is noticed in the upper limit with Soldin et al., which defined the same age group as our study ( $<2$ months) (14). Whereas the Canadian Laboratory Initiative on Pediatric Reference Intervals (CALIPER) study showed slightly lower upper reference limit, probably due to setting upper age limit to $<6$ months (12). Most of the studies reveal significant reduction of TSH in adolescence in period between 11 and 15 years of age. The differences in the age groups could be from inconsistency in applied partitioning criteria (visual and statistical analysis vs Tanner stage vs arbitrarily divid- 
A

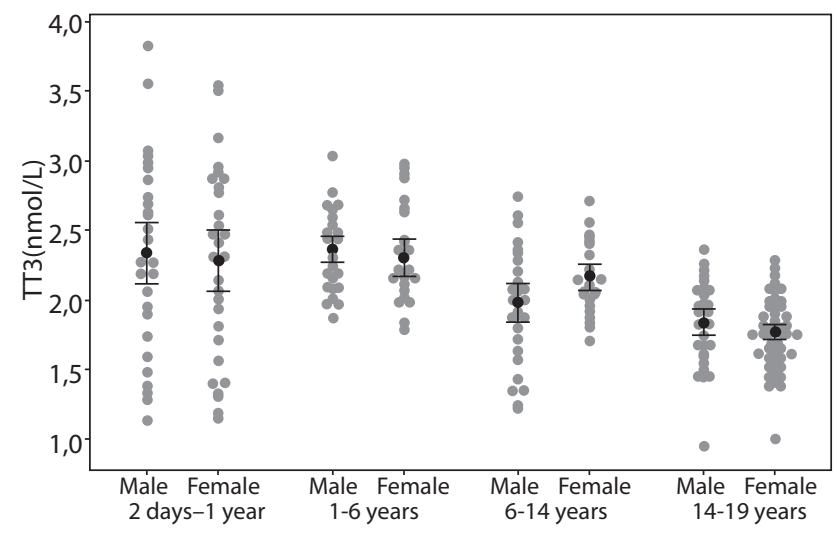

B

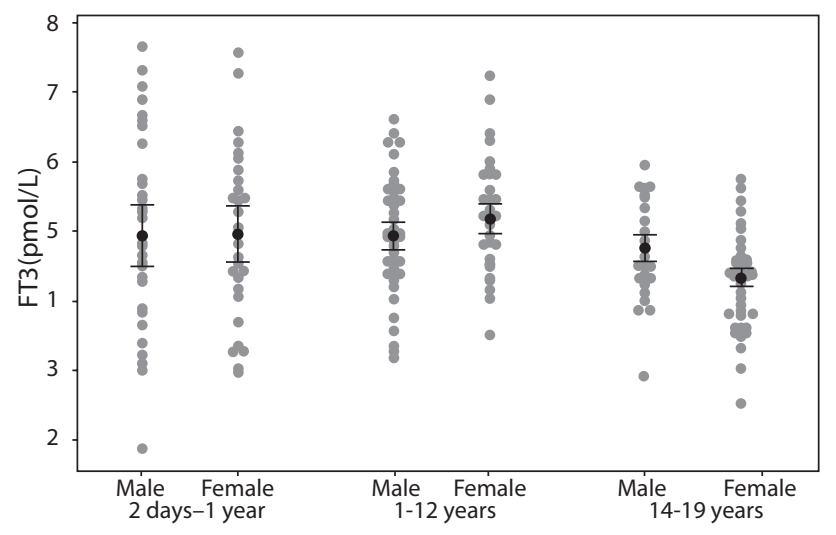

FigURE 2. Interval plots by age groups. Values are presented as mean and 95\% confidence intervals for (A) TT3 - total triiodothyronine and (B) FT3 - free triiodothyronine.

ed age groups) (10-14,24,25). Visual inspection and statistical analysis of our data confirmed TSH partitioning at the age of 14 . Regardless of different age groups, estimated Rls are similar with method-matched studies (10-14).

Our results showed TT4 and TT3 concentrations at the highest in the first year of life, then decreasing gradually towards adulthood. Interestingly, only Elmlinger et al. found moderate increase in TT4 around 7 years of age (26). Some authors reported significantly higher TT4 concentrations in females during adolescence $(12,20)$. We did not find sex related differences, which is comparable only with Elmlinger et al. (26). Due to relatively small sample number in our study, the lack of gender effect on TT4 concentration should be explored on a larger sample size. As for TT3 in the eldest group, our data did not show sex related differences, which is consistent with two other studies $(25,26)$. Even though the CALIPER study reported modest difference between sexes, our TT3 RIs are in best agreement with their results (12).

Throughout all age groups, our data showed slightly different FT3 concentration in lower reference limit, possibly due to population differences. The concentration of FT3 showed moderate changes after the first year until 11 to 14 years of age, where most other studies observed significantly higher concentrations in males $(10,12,27)$. Sex differences in adolescents can be attributed to the effects of the oestrogens, growth hormone and insulin-like growth factor 1 on enhanced peripheral conversion $(28,29)$. In contrast to other reports, our results showed that there were no sex related differences in adolescents with $\mathrm{SDR}_{\text {Sex }}<$ 0.3. However, visually plotted data showed shift to lower concentrations in adolescent females. This discrepancy could be the result of relatively small sample size, so we decided to separate adolescent FT3 Rls by sex. The FT3 concentration in adolescent are slightly lower both in lower and upper limit compared to some authors, but similar to the CALIPER eldest group $(10,12,13,27,30)$.

FT4 concentration followed TSH surge in newborns. Despite the fact that the same upper age limit at 15 days was used, our study showed significantly lower FT4 results than the CALIPER study (12). In contrast, Soldin et al. results were similar to ours, but with upper age limit set to 2 months (14). After the first year of life, FT4 remained stable until adulthood. Estimated Rls were similar to others within the Abbott group $(10,11,13,14)$. Exception was the CALIPER study which used the same age group as ours ( 1 year to $<19$ years) but found higher upper reference limit $(12,27)$.

In general, previous studies reported significant changes in thyroid function tests after birth until adulthood. The current study results showed similar pattern with all thyroid function test concentrations being the highest after birth and gradually 
falling to adult concentrations. Regardless of differences in age partitioning between studies, our results are in close agreement with RIs for TSH in method-matched studies. In contrast, our Rls for other thyroid hormones showed significant shift in upper or lower limits. CALIPER Paediatric Reference Interval Database is one of most important databases for Rls in children and adolescents as it is based on a large sample of healthy population. This certainly eases the implementation of CALIPER based Rls in many laboratories. However, population differences do exist and require re-estimation of the same, as confirmed by this study results.

Reference intervals derived from this study are limited by the fact that samples were collected from hospital in- and out- paediatric patients rather than from healthy community children. In addition, samples were collected at only one hospital centre in the biggest central region of Croatia. Although Croatian population is homogenous, regional differences still may be present. Underlying diseases could influence the results despite our

\section{References}

1. Clinical and Laboratory Standards Institute (CLSI). Defining, establishing, and verifying reference intervals in the clinical laboratory; Approved guideline - Third Edition. CLSI EP28A3c. Wayne, PA: CLSI; 2010.

2. Ozarda Y. Reference intervals: current status, recent developments and future considerations. Biochem Med (Zagreb). 2016;26:5-16. https://doi.org/10.11613/BM.2016.001

3. Hoq M, Karlaftis V, Mathews S, Burgess J, Donath SM, Carlin J, et al. A prospective, cross-sectional study to establish age-specific reference intervals for neonates and children in the setting of clinical biochemistry, immunology and haematology: the HAPPI Kids study protocol. BMJ Open. 2019;9:e025897. https://doi.org/10.1136/bmjopen-2018-025897

4. Loh TP, Sethi SK, Metz MP. Paediatric reference inter$\mathrm{val}$ and biological variation trends of thyrotropin (TSH) and free thyroxine (T4) in an Asian population. J Clin Pathol. 2015;68:642-7. https://doi.org/10.1136/jclinpath-2015-202916

5. Önsesveren I, Barjaktarovic M, Chaker L, de Rijke YB, Jaddoe VWV, van Santen HM, et al. Childhood Thyroid Function Reference Ranges and Determinants: A Literature Overview best efforts to exclude children with conditions potentially affecting thyroid hormones' metabolism. Although the recommended number of 120 samples per group was not always achieved, appropriate statistical methods according to CLSI guidelines were used (1). We did not take into account body mass index and puberty stage which could influence Rls as suggested by some authors $(16,30)$. lodine status was not measured since Croatia is a country with sufficient iodine intake (31).

To our knowledge, this is the first study conducted on paediatric patients for thyroid function tests in Croatia. Partitioning Rls by age and sex was confirmed with calculated SDR from two-level nested ANOVA. We propose Rls for widely used Abbott platform, thus giving Croatian laboratories method- and population- specific paediatric RIs for thyroid function tests that should improve clinical test interpretation. Before implementing, laboratories still need to verify our proposed RIs based on CLSI protocol defined by C28-A3 guidelines (1).

\section{Potential conflict of interest}

None declared. and a Prospective Cohort Study. Thyroid. 2017;27:1360-9. https://doi.org/10.1089/thy.2017.0262

6. Wheeler E, Choy KW, Chin LK, Wijeratne N, McNeil A, Yen T, et al. Routine free thyroxine reference intervals are suboptimal for monitoring children on thyroxine replacement therapy and target intervals need to be assay-specific. Sci Rep. 2019;9:19080. https://doi.org/10.1038/s41598-019-55690-x

7. Barth JH, Luvai A, Jassam N, Mbagaya W, Kilpatrick ES, Narayanan $D$, et al. Comparison of method-related reference intervals for thyroid hormones: studies from a prospective reference population and a literature review. Ann Clin Biochem. 2018;55:107-12. https://doi. org/10.1177/0004563217691549

8. Beckett G, MacKenzie F. Thyroid guidelines - are thyroid-stimulating hormone assays fit for purpose? Ann Clin Biochem. 2007;44:203-8. https://doi. org/10.1258/000456307780480945

9. Mirjanic-Azaric B, Jerin A, Radic Z. Thyroid stimulating hormone values of clinical decisions of hypothyroidism measurement by three different automated immunoassays. Scand J Clin Lab Invest. 2020;80:151-5. https://doi.org/10.1 080/00365513.2019.1703215 
10. Aldrimer $M$, Ridefelt $P$, Rödöö $P$, Niklasson F, Gustafsson J, Hellberg D. Reference intervals on the Abbot Architect for serum thyroid hormones, lipids and prolactin in healthy children in a population-based study. Scand J Clin Lab Invest. 2012;72:326-32. https://doi.org/10.3109/00365513.20 12.667571

11. Argente Del Castillo P, Pastor García MI, Morell-Garcia D, Martinez-Gomez L, Ballesteros MA, Barcelo A. Thyroid panel reference intervals in healthy children and adolescents: A Spanish cohort. Clin Biochem. 2021;91:39-44. https://doi. org/10.1016/j.clinbiochem.2021.01.011

12. Bailey $D$, Colantonio $D$, Kyriakopoulou L, Cohen $A H$, Chan MK, Armbruster D, et al. Marked Biological Variance in Endocrine and Biochemical Markers in Childhood: Establishment of Pediatric Reference Intervals Using Healthy Community Children from the CALIPER Cohort. Clin Chem. 2013;59:1393-405. https://doi.org/10.1373/ clinchem.2013.204222

13. Campbell PJ, Brown SJ, Kendrew P, Lewer M, Lim EM, Joseph $J$, et al. Changes in Thyroid Function Across Adolescence: A Longitudinal Study. J Clin Endocrinol Metab. 2020;105:e1162-70. https://doi.org/10.1210/clinem/dgz331

14. Soldin SJ, Cheng LL, Lam $L Y$, Werner $A$, Le AD, Soldin $O P$. Comparison of FT4 with log TSH on the Abbott Architect ci8200: Pediatric reference intervals for free thyroxine and thyroid-stimulating hormone. Clin Chim Acta. 2010;411:250-2. https://doi.org/10.1016/j.cca.2009.11.016

15. Lenicek Krleza J, Honovic L, Vlasic Tanaskovic J, Podolar S, Rimac V, Jokic A. Post-analytical laboratory work: national recommendations from the Working Group for Postanalytics on behalf of the Croatian Society of Medical Biochemistry and Laboratory Medicine. Biochem Med (Zagreb). 2019;29:020502. https://doi.org/10.11613/BM.2019.020502

16. Aypak C, Türedi Ö, Yüce A, Görpelioğlu S. Thyroid-stimulating hormone (TSH) level in nutritionally obese children and metabolic co-morbidity. J Pediatr Endocrinol. 2013;26:703-8. https://doi.org/10.1515/jpem-2012-0384

17. Boucai L, Hollowell JG, Surks MI. An Approach for Development of Age-, Gender-, and Ethnicity-Specific Thyrotropin Reference Limits. Thyroid. 2011;21:5-11. https://doi. org/10.1089/thy.2010.0092

18. Ittermann T, Khattak RM, Nauck M, Cordova CMM, Völzke H. Shift of the TSH reference range with improved iodine supply in Northeast Germany. Eur J Endocrinol. 2015;172:261-7. https://doi.org/10.1530/EJE-14-0898

19. Seror J, Amand G, Guibourdenche J, Ceccaldi P-F, Luton D. Anti-TPO Antibodies Diffusion through the Placental Barrier during Pregnancy. PLoS One. 2014;9:e84647. https://doi. org/10.1371/journal.pone.0084647

20. Kratzsch J, Schubert G, Pulzer F, Pfaeffle R, Koerner A, Dietz $A$, et al. Reference intervals for TSH and thyroid hormones are mainly affected by age, body mass index and number of blood leucocytes, but hardly by gender and thyroid autoantibodies during the first decades of life. Clin Biochem. 2008;41:1091-8. https://doi.org/10.1016/j.clinbiochem.2008.04.007
21. Clinical and Laboratory Standards Institute (CLSI). User Verification of Performance for Precision and Trueness; Approved Guideline - Second Edition. CLSI EP15-A2. Wayne, PA: CLSI; 2005.

22. Ichihara K, Boyd JC. An appraisal of statistical procedures used in derivation of reference intervals. Clin Chem Lab Med. 2010;48:1537-51. https://doi.org/10.1515/CCLM.2010.319

23. Ichihara K. Statistical considerations for harmonization of the global multicenter study on reference values. Clin Chim Acta. 2014;432:108-18. https://doi.org/10.1016/j. cca.2014.01.025

24. Bohn MK, Higgins V, Asgari S, Leung F, Hoffman B, Macri J, et al. Paediatric reference intervals for 17 Roche cobas 8000 e602 immunoassays in the CALIPER cohort of healthy children and adolescents. Clin Chem Lab Med. 2019;57:1968-79. https://doi.org/10.1515/cclm-2019-0707

25. Djemli A, Van Vliet G, Belgoudi J, Lambert M, Delvin EE. Reference intervals for free thyroxine, total triiodothyronine, thyrotropin and thyroglobulin for Quebec newborns, children and teenagers. Clin Biochem. 2004;37:328-30. https:// doi.org/10.1016/j.clinbiochem.2003.12.006

26. Elmlinger MW, Kühnel W, Lambrecht H-G, Ranke MB. Reference Intervals from Birth to Adulthood for Serum Thyroxine (T4), Triiodothyronine (T3), free T3, free T4, Thyroxine Binding Globulin (TBG) and Thyrotropin (TSH). Clin Chem Lab Med. 2001;39:973-9. https://doi.org/10.1515/ CCLM.2001.158

27. Chan MK, Seiden-Long I, Aytekin M, Quinn F, Ravalico T, Ambruster $D$, et al. Canadian Laboratory Initiative on Pediatric Reference Interval Database (CALIPER): Pediatric reference intervals for an integrated clinical chemistry and immunoassay analyzer, Abbott ARCHITECT ci8200. Clin Biochem. 2009;42:885-91. https://doi.org/10.1016/j.clinbiochem.2009.01.014

28. Marwaha RK, Tandon N, Desai AK, Kanwar R, Sastry A, Narang $A$, et al. The evolution of thyroid function with puberty: Thyroid function and puberty. Clin Endocrinol (Oxf). 2012;76:899-904. https://doi.org/10.1111/j.13652265.2011.04305.x

29. Behan LA, Monson JP, Agha A. The interaction between growth hormone and the thyroid axis in hypopituitary patients: Interaction between growth hormone and thyroid axis. Clin Endocrinol (Oxf). 2011;74:281-8. https://doi. org/10.1111/j.1365-2265.2010.03815.x

30. Radicioni AF, Tahani M, Spaziani M, Anzuini A, Piccheri $C$, Semeraro $A$, et al. Reference ranges for thyroid hormones in normal Italian children and adolescents and overweight adolescents. J Endocrinol Invest. 2013;36:326-30. https:// doi.org/10.1007/BF03347112

31. Kusić Z, Novosel SA, Dabelić N, Punda M, Rončević S, Labar $Z$, et al. Croatia has reached iodine sufficiency. J Endocrinol Invest. 2003;26:738-42. https://doi.org/10.1007/ BF03347356 